\title{
25-Hydroxyvitamin D and Total Cancer Incidence and Mortality: A Meta-Analysis of Prospective Cohort Studies
}

\author{
Jianmin Han, Xiaofei Guo, Xiao Yu, Shuang Liu, Xinyue Cui, Bo Zhang and Hui Liang * \\ Institute of Nutrition and Health, Qingdao University, Qingdao 266071, China; 18004015886@163.com (J.H.); \\ gxf@zju.edu.com (X.G.); Yuyu_3690@163.com (X.Y.); Liushuang347@163.com (S.L.); Umay_1995@163.com (X.C.); \\ zhangzhang19940516@163.com (B.Z.) \\ * Correspondence: qdlianghui@qdu.edu.cn; Tel.: + 86-0532-838-123-57
}

Received: 20 July 2019; Accepted: 20 September 2019; Published: 26 September 2019

\begin{abstract}
Epidemiological studies have suggested inconclusive associations between 25-hydroxyvitamin $\mathrm{D}$ and total cancer incidence and mortality. The aim of this study was to quantitatively assess these associations by combining results from prospective cohort studies. A systematic literature search was implemented in PubMed and Scopus databases in April 2019. Comparing the highest with the lowest categories, the multivariate-adjusted relative risks (RRs) and the corresponding $95 \%$ confidence intervals (CIs) were pooled using a random-effects model. A trend estimation was performed using a two-stage, dose-response, meta-analysis method. Twenty-three independent prospective studies were included for data synthesis. Eight studies investigated the association between 25-hydroxyvitamin D and the risk of cancer incidence (7511 events and 70,018 participants), and the summary estimate showed that 25-hydroxyvitamin $\mathrm{D}$ is marginally associated with cancer risk (Summary RR $=0.86 ; 95 \%$ CI: $0.73,1.02 ; \mathrm{I}^{2}=70.8 \% ; p=0.001$ ). Sixteen studies investigated the association between 25-hydroxyvitamin D and the risk of cancer mortality (8729 events and 101,794 participants), and a higher 25-hydroxyvitamin D concentration was inversely associated with the risk of cancer mortality (Summary $\mathrm{RR}=0.81 ; 95 \% \mathrm{CI}: 0.71,0.93 ; \mathrm{I}^{2}=48.8 \%, p=0.012$ ). Dose-response analysis indicated that the risk of cancer incidence was reduced by $7 \%$ (RRs $=0.93$; $95 \%$ CI: 0.91, 0.96), and the risk of cancer mortality was reduced by $2 \%$ (RRs $=0.98 ; 95 \%$ CI: $0.97,0.99$ ), with each $20 \mathrm{nmol} / \mathrm{L}$ increment of 25-hydroxyvitamin D concentration. This meta-analysis provides evidence that a higher 25-hydroxyvitamin D concentration is associated with a lower cancer incidence and cancer mortality.
\end{abstract}

Keywords: vitamin D; cancer incidence; cancer mortality; prospective study; meta-analysis

\section{Introduction}

Cancer is the leading cause of global morbidity and mortality, with approximately 18.1 million new cancer cases and 9.6 million cancer deaths in 2018 [1]. The number of people who died of cancer ranks second, second only to the number of deaths from cardiovascular and cerebrovascular diseases worldwide [2,3]. In recent years, great progress has been made in the prevention and treatment of certain cancers [4-6]. Despite these advances, the burden of cancer is increasing due to the increasing global population and ageing, as well as risk factors, such as smoking, obesity and unhealthy dietary patterns. Therefore, it is necessary to identify many aspects of the beneficial factors for cancer prevention.

As a secosteroid hormone, the biologically active metabolite of vitamin $\mathrm{D}$ is attributed to 1,25-dihydroxyvitamin $\mathrm{D}(1,25(\mathrm{OH}) 2 \mathrm{D})$, which is synthesized from the circulating 25-hydroxyvitamin 
D $(25(\mathrm{OH}) \mathrm{D})$ by 1a-hydroxylase (CYP27B1). The classical biological function of vitamin D is to regulate calcium and phosphorus balance and maintain bone health. Recent studies have found that it also plays an important role in anti-inflammatory, anti-fibrosis and immunoregulation processes, and it is also involved in maintaining the growth and development of the body and regulating cell proliferation, differentiation and apoptosis [7-9]. As early as 1980, an epidemiological study proposed that vitamin D may have anti-cancer properties [10]. Since then, numerous studies have supported this hypothesis [11-13]. The anti-cancer effect of vitamin D might be related to its regulation of cell proliferation and differentiation, growth factor gene expression, and signal transduction and apoptosis [14-19]. Extensive investigations, both in vitro and in vivo, have demonstrated that vitamin $\mathrm{D}$ is associated with cancer [20-23]. In addition, there is strong evidence, from cell experiments and animal studies, that supports the anti-tumor effects of vitamin D [14,24,25]. However, the results from prospective cohort studies have been inconsistent.

In fact, there were already several meta-analyses of prospective studies about cancer incidence or mortality, existing meta-analysis also yield inconsistent results [26-29]. Several prospective cohort studies recently explored the associations between 25-hydroxyvitamin D and cancer risk and mortality, while the results remain controversial [30-33]. However, the meta-analysis of prospective studies has not been updated in recent years. Therefore, to provide a more comprehensive, up-to-date assessment of the associations between 25-hydroxyvitamin D and cancer risk and mortality, we conducted a systematic review and meta-analysis to quantitatively assess these associations. In addition, a dose-response meta-analyses were performed to explore the trend estimation.

\section{Materials and Methods}

\subsection{Search Strategy and Inclusion Criteria}

A systematic literature search was performed in the Cochrane library, Embase and PubMed databases until April, 2019 using the search query: Vitamin D, VD, 25-hydroxyvitamin D, 25(OH)D, 1,25-dihydroxyvitamin $\mathrm{D}$ or 1,25(OH)2D, paired with cancer, tumor, neoplasm, mortality, incidence, risk, and occurrence.

Two authors independently performed the literature search and identified potential studies from the title, abstract and full-text. The inclusion criteria were prospective studies (comprising the prospective cohort and, nested case-control studies). The exposure of interest was the serum $25(\mathrm{OH}) \mathrm{D}$ concentration or plasma $25(\mathrm{OH}) \mathrm{D}$ concentration, and the end point of interestwas the number of cancer patients or deaths due to cancer during follow-ups.

\subsection{Data Extraction and Quality Assessment}

For the identified studies, data extraction was conducted by two investigators, and any discrepancy was resolved via discussion. The characteristics, including the first author's surname, publication year, geographic region, duration of follow-up, mean age at the baseline, number of participants and cases, age of the participants, relative risk (RR), with the corresponding $95 \%$ confidence interval (CI), and the assay used to measure $25(\mathrm{OH}) \mathrm{D}$, and covariates, adjusted for in the analyses, were extracted from the eligible studies. While most of the original studies used the lowest dose group as the reference group, a few used other groups as the reference group, so we converted this kind of study into the lowest dose group, as the reference group [34]. The Newcastle-Ottawa Scale criteria, with a 9-star system, was adopted to perform the quality assessment. The full score was defined as 9 stars, and a study was classified as low, moderate and high-quality using 0-3, 4-6 and 7-9 stars, respectively [35]. The assessments were conducted by two investigators, any discrepancy was resolved with the third investigator (Hui Liang) to reach agreement. 


\subsection{Statistical Analysis}

$\mathrm{RR}$ was regarded as the common risk estimate for the association between $25(\mathrm{OH}) \mathrm{D}$ and cancer risk and mortality. Considering that the eligible studies were prospective studies, thus, odds ratio (OR) or HR was directly considered as RR for data synthesis. Multivariate-adjusted RRs, with the corresponding 95\% CIs for the highest versus lowest category, were logarithm transformed, and the summary RR was calculated using a random-effects model, which was weighted by the inverse of the variance of the RRs. Studies including three or more 25(OH)D categories were eligible for dose-response analysis [36]. The median concentration of $25(\mathrm{OH}) \mathrm{D}$, assigned in respective quantiles, was extracted. The midpoint of the lower and upper categories was regarded as the 25(OH)D concentration of the quantile, if the media concentration was not provided. The concentration of $25(\mathrm{OH}) \mathrm{D}$ was defined as 1.2 times higher than the highest boundary, if the highest quantile was open-ended. Meanwhile, the 25(OH)D concentration of the lowest quantile (the reference) was set as 0 in each study [37]. We performed a random-effects, dose-response, meta-analysis to estimate the potential curvilinear relation. A two-stage, random-effects, dose-response analysis was carried out to estimate the associations between 25-hydroxyvitamin $\mathrm{D}$ and cancer incidence and mortality. To estimate the potential curvilinear (non-linear) associations between 25-hydroxyvitamin D concentration and cancer risk and cancer mortality, a restricted cubic spline model was applied, with 3 knots at fixed percentiles of the 25-hydroxyvitamin D subclasses distribution $(25 \%$, $50 \%$ and $75 \%$ ) [38]. P for non-linearity is obtained by testing the null hypothesis that the regression coefficients of the spline transformations are all equal to zero [39]. $\mathrm{I}^{2}$ statistic was used to estimate the heterogeneity between studies. To examine the potential sources of heterogeneity, subgroup and univariate meta-regression analyses, including duration of follow-up, region, study quality and mean age of participants, was implemented based on the information of these studies. In order to assess whether a study had an undue influence on the summary estimates, we deleted one study at a time and recalculated the summary estimates. The Egger's test was used to assess publication bias $(p<0.1$ [40] is significant). Statistical analysis was performed using STATA 11.0 (STATA CORP, College station, TX, USA). The $p$ value was two-tailed and the significance level was 0.05 .

\section{Results}

\subsection{Literature Search and Study Characteristics}

The flow chart of the literature search is presented in Figure 1. We identified 10,585 citations from PubMed and 13,979 from Scopus. Among these, 15,026 citations remained, after the exclusion of duplicates, and 14,932 citations were excluded by screening the titles and abstracts, leaving 94 articles for full-text examination. Of these, 71 articles were excluded, because they did not satisfy the inclusion criteria (e.g., they did not provide sufficient data, an adequate study design or a relevant review). Finally, 23 articles were included for data synthesis.

Basic information concerning the eligible studies is listed in Tables 1 and 2. A total of 8 prospective cohort studies were included in the meta-analysis of total cancer incidence (7511 events and 70,018 participants) [13,30-32,41-44], and 16 prospective cohort studies were included in the meta-analysis of total cancer mortality (8729 events and 10,794 participants) [33,43,45-58]. Eight prospective cohort studies were conducted in the US [44,47,48,50,52,55,57], thirteen were performed in Europe [13,32,33, $41-43,45,49,51,53,54,56,58]$, and the remaining studies were executed in Asia [30,31,46]. The level of covariate adjustment in the individual studies differed, but all studies adjusted for age, sex and some indicators relating to tumor spreading. Most studies measured the $25(\mathrm{OH}) \mathrm{D}$ serum concentration with immunoassays $[30,32,41,46,48,50,53,55,57]$ or mass spectrometry $[31,42-44,47,49,52,56]$. Besides, other studies measured $25(\mathrm{OH}) \mathrm{D}$ serum concentration using a radioimmunoassay $[13,45,51]$ and competitive protein-binding assay $[33,54,58]$. Five studies were limited to males $[13,33,43,45,48]$ and two to females [47,52]. On the basis of the Newcastle-Ottawa scale criteria, 15 prospective studies were classified as high-quality $[13,30,31,41,46,47,49-51,53-58]$, and the remaining studies were classified as moderate-quality [32,42-45,48,52] (Supplementary Tables S1 and S2). 


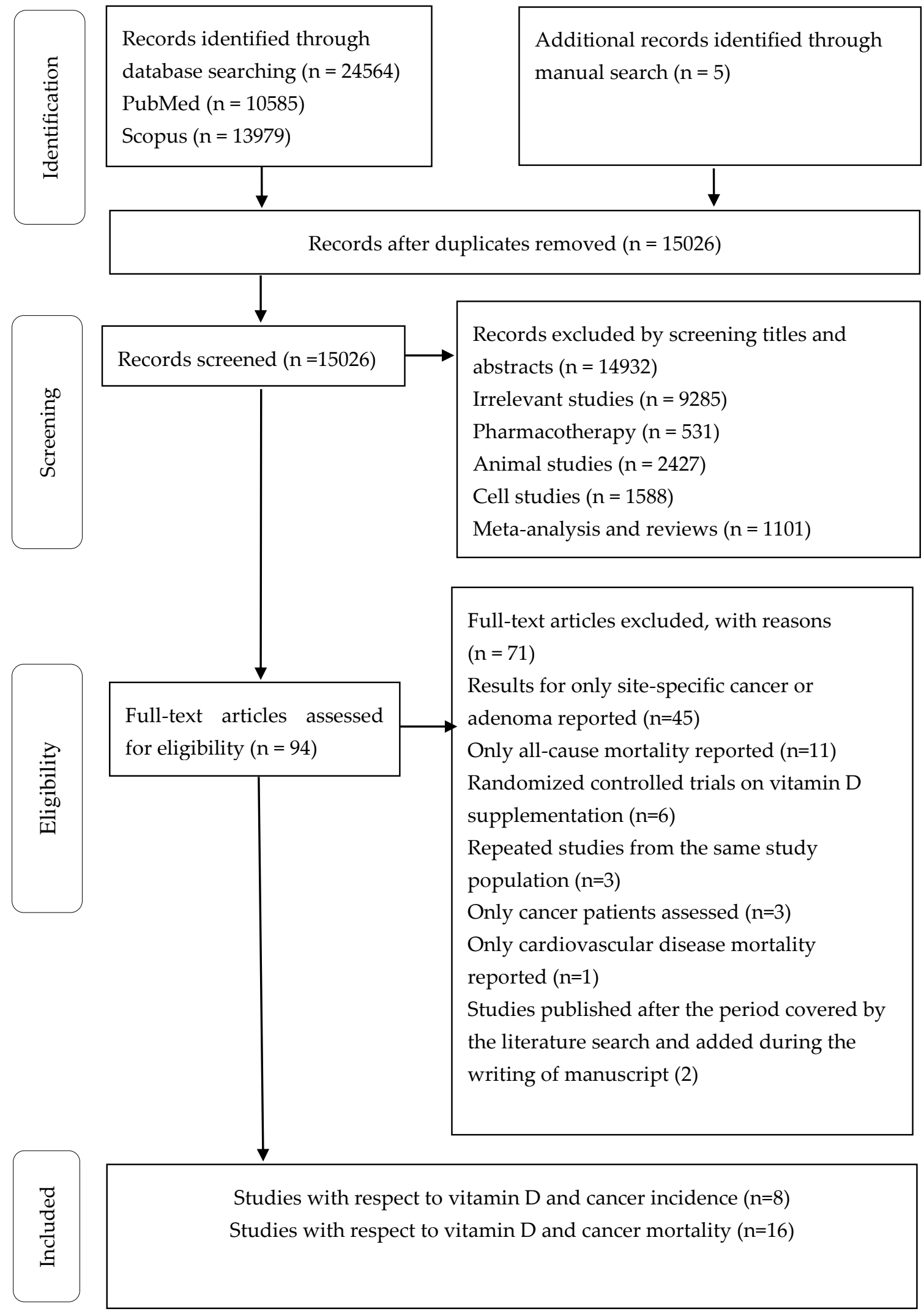

Figure 1. Flow chart of the study selection process. 
Table 1. Prospective studies reporting on the association of circulating $25(\mathrm{OH}) \mathrm{D}$ serum concentration with total cancer incidence ${ }^{\mathrm{a}}$.

\begin{tabular}{|c|c|c|c|c|c|c|c|}
\hline $\begin{array}{l}\text { First Author and } \\
\text { Cohort }\end{array}$ & $\begin{array}{c}\text { Publication } \\
\text { Year and Region }\end{array}$ & $\begin{array}{l}\text { Mean Age } \\
\text { (Gender) }\end{array}$ & $\begin{array}{l}\text { Subjects } \\
\text { (Cases) }\end{array}$ & $\begin{array}{l}\text { Follow-Up } \\
\text { Period }\end{array}$ & $\begin{array}{l}\text { Exposure } \\
\text { Measure }\end{array}$ & Outcome Ascertainment & Covariates Adjusted \\
\hline $\begin{array}{l}\text { Afzal [13] } \\
\text { CCHS }\end{array}$ & $\begin{array}{c}\text { 2013, } \\
\text { Denmark }\end{array}$ & $\begin{array}{l}57.7 \\
(\mathrm{M})\end{array}$ & $\begin{array}{c}9791 \\
(1081)\end{array}$ & $28 \mathrm{y}$ & radioimmunoassay & $\begin{array}{l}\text { obtained from the Danish } \\
\text { Cancer Registry }\end{array}$ & $\begin{array}{l}\text { age, sex, pack-years, BMI, alcohol } \\
\text { consumption, leisure time and work-related } \\
\text { physical activity, duration of education and } \\
\text { month of blood sample }\end{array}$ \\
\hline $\begin{array}{l}\text { Budhathoki [31], } \\
\text { JPHC }\end{array}$ & $\begin{array}{l}2018, \\
\text { Japan }\end{array}$ & $\begin{array}{l}53.7 \\
\text { (Both) }\end{array}$ & $\begin{array}{l}33,736 \\
(3301)\end{array}$ & $19 y$ & $\begin{array}{l}\text { chemiluminescent } \\
\text { enzyme } \\
\text { immunoassay }\end{array}$ & $\begin{array}{l}\text { obtained from local hospitals } \\
\text { and population-based cancer } \\
\text { registries }\end{array}$ & $\begin{array}{l}\text { age, sex, body mass index, smoking, alcohol } \\
\text { use, physical activity, family history of } \\
\text { cancer, and reported history of diabetes. }\end{array}$ \\
\hline $\begin{array}{l}\text { Lin [32], } \\
\text { CSPPT }\end{array}$ & $\begin{array}{l}\text { 2018, } \\
\text { China }\end{array}$ & $\begin{array}{l}61.8 \\
\text { (Both) }\end{array}$ & $\begin{array}{c}462 \\
(231)\end{array}$ & $4.5 \mathrm{y}$ & $\begin{array}{l}\text { liquid } \\
\text { chromatography } \\
\text { tandem mass } \\
\text { spectrometry }\end{array}$ & $\begin{array}{l}\text { diagnosed based on either } \\
\text { positive pathologic findings } \\
\text { or specific clinical } \\
\text { manifestations }\end{array}$ & $\begin{array}{l}\text { age, sex, treatment group, and study site, } \\
\text { and adjusted for BMI, smoking status, } \\
\text { alcohol consumption, baseline SBP and DBP, } \\
\text { time-averaged SBP and DBP during } \\
\text { treatment, baseline fasting blood glucose, } \\
\text { total cholesterol, triglycerides, season of } \\
\text { blood collection, plasma calcium levels, } \\
\text { folate, vitamin } \mathrm{B}_{12} \text {, vitamin A, vitamin E and } \\
\text { vitamin } \mathrm{K}\end{array}$ \\
\hline $\begin{array}{l}\text { Skaaby [42], } \\
\text { Monica10, Inter99, } \\
\text { and Health2006 }\end{array}$ & $\begin{array}{c}\text { 2014, } \\
\text { Denmark }\end{array}$ & $\begin{array}{c}60.5 \\
\text { (Both) }\end{array}$ & $\begin{array}{l}12,204 \\
(1248)\end{array}$ & $11.3 \mathrm{y}$ & $\begin{array}{l}\text { chemiluminescent } \\
\text { enzyme } \\
\text { immunoassay }\end{array}$ & $\begin{array}{l}\text { obtained from the Danish } \\
\text { Central Personal Register }\end{array}$ & $\begin{array}{l}\text { study group (no intervention (participants } \\
\text { from Monica10), lifestyle counseling (group } \\
\text { B from Inter99), lifestyle and group } \\
\text { counseling (group A from Inter99)), gender, } \\
\text { education, season, physical activity, smoking } \\
\text { habits, alcohol intake, intake of fish, and BMI }\end{array}$ \\
\hline $\begin{array}{l}\text { Cheney [33], } \\
\text { KORA }\end{array}$ & $\begin{array}{l}\text { 2018, } \\
\text { Germany }\end{array}$ & $\begin{array}{c}53.5 \\
\text { (Both) }\end{array}$ & $\begin{array}{c}2003 \\
(69)\end{array}$ & $7 y$ & $\begin{array}{c}\text { enzyme } \\
\text { immunoassay }\end{array}$ & $\begin{array}{l}\text { identified using a } \\
\text { standardized interview (FF4) } \\
\text { by trained medical personnel. }\end{array}$ & $\begin{array}{l}\text { age, sex, BMI, season of blood draw, physical } \\
\text { activity, smoking status, smoking status } \\
\text { alcohol consumption and vitamin D } \\
\text { supplementation }\end{array}$ \\
\hline $\begin{array}{l}\text { Boer [45], } \\
\text { CHS }\end{array}$ & $\begin{array}{l}\text { 2012, } \\
\text { USA }\end{array}$ & $\begin{array}{l}74.0 \\
\text { (Both) }\end{array}$ & $\begin{array}{l}1621 \\
(335)\end{array}$ & $15 \mathrm{y}$ & $\begin{array}{l}\text { high-performance } \\
\text { liquid } \\
\text { chromatography } \\
\text { tandem mass } \\
\text { spectrometry }\end{array}$ & $\begin{array}{l}\text { obtained from available } \\
\text { hospital discharge summaries, } \\
\text { diagnostic test records, and } \\
\text { consultation reports }\end{array}$ & $\begin{array}{l}\text { age, sex, clinical site, smoking, body mass } \\
\text { index, and physical activity }\end{array}$ \\
\hline
\end{tabular}


Table 1. Cont

\begin{tabular}{|c|c|c|c|c|c|c|}
\hline $\begin{array}{c}\text { First Author and } \\
\text { Cohort }\end{array}$ & $\begin{array}{c}\text { Publication } \\
\text { Year and Region }\end{array}$ & $\begin{array}{l}\text { Mean Age } \\
\text { (Gender) }\end{array}$ & $\begin{array}{l}\text { Subjects } \\
\text { (Cases) }\end{array}$ & $\begin{array}{l}\text { Follow-Up } \\
\text { Period }\end{array}$ & Outcome Ascertainment & Covariates Adjusted \\
\hline $\begin{array}{l}\text { Michaelsson [44], } \\
\text { ULSAM }\end{array}$ & $\begin{array}{l}2010 \\
\text { Sweden }\end{array}$ & $\begin{array}{c}71 \\
(\mathrm{M})\end{array}$ & $\begin{array}{l}1194 \\
(373)\end{array}$ & $12.7 \mathrm{y}$ & $\begin{array}{l}\text { high-performance } \\
\quad \text { liquid } \\
\text { chromatography-tanderned from Swedish } \\
\text { mass spectrometry }\end{array}$ & $\begin{array}{l}\text { age, weight, height, calcium intake, season of } \\
\text { blood draw, social class, smoking status, } \\
\text { leisure physical activity, self-perceived } \\
\text { health, diabetes mellitus, other endocrine } \\
\text { disease, hematologic diseases, dermatoses, } \\
\text { infectious disease, musculoskeletal disease, } \\
\text { psychiatric disease, respiratory disease, } \\
\text { kidney or urinary disease, gastrointestinal } \\
\text { disease, supplemental vitamin D use, total } \\
\text { vitamin D intake, fish intake, plasma } \\
\text { parathyroid hormone, plasma cystatin C, } \\
\text { plasma C-reactive protein, serum calcium, } \\
\text { serum phosphate, plasma troponin I, plasma } \\
\text { N-terminal pro brain natriuretic peptide, } \\
\text { plasma cholesterol, plasma triglycerides, } \\
\text { plasma HDL cholesterol, plasma retinol, } \\
\text { plasma insulin, total energy intake, and } \\
\text { alcohol intake and systolic blood pressure, } \\
\text { diastolic blood pressure, lipid-lowering } \\
\text { treatment, and antihypertensive treatment. }\end{array}$ \\
\hline $\begin{array}{c}\text { Ordonez -Mena } \\
\text { [27] }\end{array}$ & $\begin{array}{c}2013 \\
\text { Germany }\end{array}$ & $\begin{array}{c}63 \\
\text { (Both) }\end{array}$ & $\begin{array}{l}9007 \\
(873)\end{array}$ & $8 \mathrm{y}$ & 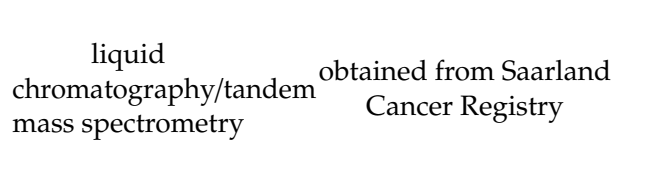 & $\begin{array}{l}\text { Age, sex, multivitamin use, fish } \\
\text { consumption, red meat consumption, daily } \\
\text { fruit intake, daily vegetables intake, BMI, } \\
\text { scholarly education, physical activity, } \\
\text { smoking, and family history of cancer }\end{array}$ \\
\hline
\end{tabular}


Table 2. Prospective studies reporting on the association of circulating $25(\mathrm{OH}) \mathrm{D}$ serum concentration with total cancer mortality $\mathrm{b}$.

\begin{tabular}{|c|c|c|c|c|c|c|c|}
\hline First Author & $\begin{array}{c}\text { Publication } \\
\text { Year and Region }\end{array}$ & $\begin{array}{l}\text { Mean Age } \\
\text { (Gender) }\end{array}$ & $\begin{array}{c}\text { Subjects } \\
\text { (Cases) }\end{array}$ & $\begin{array}{l}\text { Follow-Up } \\
\text { Period }\end{array}$ & Exposure Measure & Outcome Ascertainment & Covariates Adjusted \\
\hline $\begin{array}{l}\text { Lee [46], } \\
\text { EMAS }\end{array}$ & $\begin{array}{l}\text { 2013, } \\
\text { Europe }\end{array}$ & $\begin{array}{l}60 \\
(\mathrm{M})\end{array}$ & $\begin{array}{c}2816 \\
(28)\end{array}$ & $4.3 \mathrm{y}$ & radioimmunoassay & $\begin{array}{l}\text { Obtained from death } \\
\text { certificates, death registers } \\
\text { and medical/hospital records. }\end{array}$ & $\begin{array}{l}\text { age, center, smoking status, alcohol } \\
\text { consumption, self-reported morbidities, } \\
\text { Physical Activity Scale for the Elderly score, } \\
\text { Reuben's Physical Performance Test rating } \\
\text { and serum creatinine }\end{array}$ \\
\hline $\begin{array}{l}\text { Lin [47], } \\
\text { GPTL }\end{array}$ & $\begin{array}{r}2012, \\
\text { China }\end{array}$ & $\begin{array}{c}56.5 \\
\text { (Both) }\end{array}$ & $\begin{array}{c}110 \\
(217)\end{array}$ & $24 \mathrm{y}$ & enzyme immunoassay & $\begin{array}{l}\text { Obtained from records of the } \\
\text { village doctors, evaluated and } \\
\text { verified by a panel of } \\
\text { Chinese experts }\end{array}$ & $\begin{array}{l}\text { age and sex, with additional adjustment by } \\
\text { separate continuous age variables for each } \\
\text { stratum as well as sex, hypertension, tobacco } \\
\text { smoking, BMI, and alcohol consumption. }\end{array}$ \\
\hline $\begin{array}{l}\text { Wong [48], } \\
\text { CAIFOS }\end{array}$ & $\begin{array}{l}2015 \\
\text { US }\end{array}$ & $\begin{array}{l}75.1 \\
(\mathrm{~F})\end{array}$ & $\begin{array}{l}1188 \\
(84)\end{array}$ & $10 \mathrm{y}$ & $\begin{array}{l}\text { liquid chromatography } \\
\text { tandem mass } \\
\text { spectrometry }\end{array}$ & $\begin{array}{l}\text { Obtained from the hospital } \\
\text { death certificates and } \\
\text { previous medical history, and } \\
\text { the coded discharge } \\
\text { diagnosis data }\end{array}$ & $\begin{array}{l}\text { age, diastolic blood pressure, systolic blood } \\
\text { pressures, previous and current smoker, BMI, } \\
\text { daily alcohol use, co-morbidities, season at } \\
\text { recruitment, treatment allocation, laboratory } \\
\text { measurements }\end{array}$ \\
\hline $\begin{array}{l}\text { Weinstein [34], } \\
\text { ATBC }\end{array}$ & $\begin{array}{l}\text { 2018, } \\
\text { Finland }\end{array}$ & $\begin{array}{l}59.5 \\
(\mathrm{M})\end{array}$ & $\begin{array}{c}4616 \\
(2884)\end{array}$ & $28 \mathrm{y}$ & $\begin{array}{c}\text { competitive } \\
\text { chemiluminescence } \\
\text { immunoassay/ } \\
\text { radioimmunoassay/ liquid } \\
\text { chromatography tandem } \\
\text { mass spectrometry }\end{array}$ & $\begin{array}{l}\text { obtained from Finnish } \\
\text { Cancer Registry }\end{array}$ & $\begin{array}{l}\text { BMI, number of cigarettes smoked per day, } \\
\text { years of smoking, physical activity, serum } \\
\text { cholesterol, history of diabetes, family } \\
\text { history of cancer, systolic blood pressure, } \\
\text { trial intervention group, and calendar year } \\
\text { of diagnosis }\end{array}$ \\
\hline $\begin{array}{l}\text { Cawthon [49], } \\
\text { MrOS }\end{array}$ & $\begin{array}{l}2010 \\
\text { USA }\end{array}$ & $\begin{array}{l}73.7 \\
(\mathrm{M})\end{array}$ & $\begin{array}{l}1490 \\
(97)\end{array}$ & $7.3 \mathrm{y}$ & $\begin{array}{l}\text { chemiluminescence } \\
\text { immunoassay }\end{array}$ & $\begin{array}{l}\text { obtained from six U.S. clinical } \\
\text { centers through death } \\
\text { certificates and discharge } \\
\text { summaries }\end{array}$ & $\begin{array}{l}\text { age, clinic, season of blood collection, serum } \\
\text { calcium and phosphate, GFR, percentage } \\
\text { body fat, weight, race, health status, } \\
\text { presence of at least one medical condition, } \\
\text { alcohol use, education, activity level, marital } \\
\text { status, and presence of a functional or } \\
\text { mobility limitation }\end{array}$ \\
\hline $\begin{array}{l}\text { Hutchinson [42], } \\
\text { TS }\end{array}$ & $\begin{array}{l}2010 \\
\text { Norway }\end{array}$ & $\begin{array}{l}\text { Nonsmoker } \\
61 \\
\text { Smoker } \\
57.2 \\
\text { (Both) }\end{array}$ & $\begin{array}{l}7161 \\
(498)\end{array}$ & $13 y$ & mass spectrometry & $\begin{array}{l}\text { obtained from Norway } \\
\text { Cancer Registry }\end{array}$ & $\begin{array}{l}\text { age, gender, season, BMI, physical activity } \\
\text { score, diabetes, hypertension, serum } \\
\text { creatinine, prior cardiovascular disease and } \\
\text { prior cancer }\end{array}$ \\
\hline
\end{tabular}


Table 2. Cont.

\begin{tabular}{|c|c|c|c|c|c|c|c|}
\hline First Author & $\begin{array}{c}\text { Publication } \\
\text { Year and Region }\end{array}$ & $\begin{array}{l}\text { Mean Age } \\
\text { (Gender) }\end{array}$ & $\begin{array}{c}\text { Subjects } \\
\text { (Cases) }\end{array}$ & $\begin{array}{l}\text { Follow-Up } \\
\text { Period }\end{array}$ & Exposure Measure & Outcome Ascertainment & Covariates Adjusted \\
\hline $\begin{array}{l}\text { Freedman [51], } \\
\text { NHANES III }\end{array}$ & $\begin{array}{l}2010 \\
\text { USA }\end{array}$ & $\begin{array}{c}44 \\
\text { (Both) }\end{array}$ & $\begin{array}{c}16,819 \\
(884)\end{array}$ & $12.5 \mathrm{y}$ & $\begin{array}{l}\text { electrochemiluminescence } \\
\text { immunoassay }\end{array}$ & $\begin{array}{l}\text { obtained from National } \\
\text { Center for Health Statistics of } \\
\text { the Centers for Disease } \\
\text { Control and Prevention }\end{array}$ & $\begin{array}{l}\text { age, race/ ethnicity, smoking history, } \\
\text { and BMI. }\end{array}$ \\
\hline $\begin{array}{l}\text { Pilz [52], } \\
\text { LURIC }\end{array}$ & $\begin{array}{l}2008 \\
\text { Germany }\end{array}$ & $\begin{array}{l}62.7 \\
\text { (Both) }\end{array}$ & $\begin{array}{l}3257 \\
(95)\end{array}$ & $7.75 \mathrm{y}$ & radioimmunoassay & $\begin{array}{l}\text { obtained from local } \\
\text { person registries }\end{array}$ & $\begin{array}{l}\text { age, gender, season, BMI, active smokers, } \\
\text { retinol, exercise tertiles, beer and wine } \\
\text { consumption, and diabetes mellitus. }\end{array}$ \\
\hline $\begin{array}{l}\text { Eaton [53], } \\
\text { WHI }\end{array}$ & $\begin{array}{l}2011 \\
\text { USA }\end{array}$ & $\begin{array}{c}65.8 \\
(\mathrm{~F})\end{array}$ & $\begin{array}{c}2429 \\
(62)\end{array}$ & $8 \mathrm{y}$ & $\begin{array}{l}\text { high-performance liquid } \\
\text { chromatography }\end{array}$ & $\begin{array}{c}\text { obtained from the Women's } \\
\text { Health Initiative }\end{array}$ & $\begin{array}{l}\text { age, season, ethnicity, CaD trial indicator, } \\
\text { education, smoking status, current aspirin } \\
\text { use, history of fracture, waist circumference, } \\
\text { BMI, physical activity, and use of vitamin } \\
\text { D supplements. }\end{array}$ \\
\hline $\begin{array}{l}\text { Skaaby [54], } \\
\text { Monica10 and } \\
\text { Inter99. }\end{array}$ & $\begin{array}{c}2012 \\
\text { Denmark }\end{array}$ & $\begin{array}{c}49.8 \\
\text { (Both) }\end{array}$ & $\begin{array}{l}9146 \\
(301)\end{array}$ & $10 \mathrm{y}$ & $\begin{array}{l}\text { chemiluminescence } \\
\text { immunoassay }\end{array}$ & $\begin{array}{l}\text { obtained from Danish } \\
\text { Registry of Causes of Death }\end{array}$ & $\begin{array}{l}\text { study group (no intervention (participants } \\
\text { from Monica10), lifestyle counseling (group } \\
\text { B from Inter99), lifestyle and group } \\
\text { counseling (group A from Inter99)), gender, } \\
\text { education, season of blood sample, intake of } \\
\text { fish, physical activity, smoking, BMI and } \\
\text { alcohol consumption. }\end{array}$ \\
\hline $\begin{array}{l}\text { Signorello [56], } \\
\text { SCCS }\end{array}$ & $\begin{array}{l}2012 \\
\text { USA }\end{array}$ & $\begin{array}{l}59.5 \\
\text { (Both) }\end{array}$ & $\begin{array}{l}3704 \\
(954)\end{array}$ & $7 y$ & $\begin{array}{l}\text { chemiluminescence } \\
\text { immunoassay }\end{array}$ & $\begin{array}{l}\text { identified by Social Security } \\
\text { Administration's Death } \\
\text { Master File and the National } \\
\text { Death Index }\end{array}$ & $\begin{array}{l}\text { gender, race, age, community health center } \\
\text { enrollment site, date of blood collection, BMI, } \\
\text { smoking, physical activity, and } \\
\text { household income. }\end{array}$ \\
\hline $\begin{array}{c}\text { Khaw [57], } \\
\text { - }\end{array}$ & $\begin{array}{c}2014 \\
\text { UK }\end{array}$ & $\begin{array}{c}62 \\
\text { (Both) }\end{array}$ & $\begin{array}{l}14,641 \\
(1086)\end{array}$ & $13 \mathrm{y}$ & mass spectrometry & $\begin{array}{l}\text { obtained fromNational } \\
\text { Cancer Registry for } \\
\text { incident Cancer }\end{array}$ & $\begin{array}{l}\text { age, sex, month, BMI, physical activity, } \\
\text { smoking, alcohol, vitamin C, diabetes, } \\
\text { history of cardiovascular disease, history of } \\
\text { cancer, social class, and education }\end{array}$ \\
\hline
\end{tabular}


Table 2. Cont.

\begin{tabular}{|c|c|c|c|c|c|c|c|}
\hline First Author & $\begin{array}{c}\text { Publication } \\
\text { Year and Region }\end{array}$ & $\begin{array}{l}\text { Mean Age } \\
\text { (Gender) }\end{array}$ & $\begin{array}{l}\text { Subjects } \\
\text { (Cases) }\end{array}$ & $\begin{array}{l}\text { Follow-Up } \\
\text { Period }\end{array}$ & Exposure Measure & Outcome Ascertainment & Covariates Adjusted \\
\hline $\begin{array}{l}\text { Kritchevsky [58], } \\
\text { Health ABC }\end{array}$ & $\begin{array}{c}2012 \\
\text { US }\end{array}$ & $\begin{array}{l}74.7 \\
\text { (Both) }\end{array}$ & $\begin{array}{l}2638 \\
(218)\end{array}$ & $8.5 \mathrm{y}$ & immunoassay & $\begin{array}{c}\text { identified by medical records, } \\
\text { death certificates, proxy } \\
\text { information, and } \\
\text { autopsy reports }\end{array}$ & $\begin{array}{l}\text { age, gender, race, education, season, field } \\
\text { center, smoking status, pack years, alcohol } \\
\text { consumption, body mass index, time } \\
\text { walking, usual 20m walking speed, } \\
\text { estimated glomerular filtration rate, } \\
\text { cognition, depressive symptoms, IL-6, } \\
\text { cholesterol, and prevalent diabetes, } \\
\text { hypertension, } \\
\text { cardiovascular disease, cancer, or } \\
\text { lung disease. }\end{array}$ \\
\hline $\begin{array}{l}\text { Rohrmann [59], } \\
\text { Swiss MONICA }\end{array}$ & 2012 & $\begin{array}{c}47.1 \\
\text { (Both) }\end{array}$ & $\begin{array}{l}3198 \\
(188)\end{array}$ & $18 \mathrm{y}$ & protein-bound assay & $\begin{array}{l}\text { obtained from Swiss } \\
\text { National Cohort }\end{array}$ & $\begin{array}{l}\text { age, sex, sunlight exposure, systolic blood } \\
\text { pressure, smoking status, nationality }\end{array}$ \\
\hline $\begin{array}{l}\text { Michaelsso [44], } \\
\text { ULSAM }\end{array}$ & $\begin{array}{l}2010 \\
\text { Sweden }\end{array}$ & $\begin{array}{c}71 \\
(\mathrm{M})\end{array}$ & $\begin{array}{l}1194 \\
(164)\end{array}$ & $12.7 \mathrm{y}$ & $\begin{array}{l}\text { high-performance liquid } \\
\text { chromatography-tandem } \\
\text { mass spectrometry }\end{array}$ & $\begin{array}{l}\text { obtained from Swedish } \\
\text { National Cancer Registry and } \\
\text { Cause of Death Registry }\end{array}$ & $\begin{array}{l}\text { age, weight, height, calcium intake, season of } \\
\text { blood draw, social class, smoking status, } \\
\text { leisure physical activity, self-perceived } \\
\text { health, diabetes mellitus, other endocrine } \\
\text { disease, hematologic diseases, dermatoses, } \\
\text { infectious disease, musculoskeletal disease, } \\
\text { psychiatric disease, respiratory disease, } \\
\text { kidney or urinary disease, gastrointestinal } \\
\text { disease, supplemental vitamin D use, total } \\
\text { vitamin D intake, fish intake, plasma } \\
\text { parathyroid hormone, plasma cystatin C, } \\
\text { plasma C-reactive protein, serum calcium, } \\
\text { serum phosphate, plasma troponin I, plasma } \\
\text { N-terminal pro brain natriuretic peptide, } \\
\text { plasma cholesterol, plasma triglycerides, } \\
\text { plasma HDL cholesterol, plasma retinol, } \\
\text { plasma insulin, total energy intake, and } \\
\text { alcohol intake and systolic blood pressure, } \\
\text { diastolic blood pressure, lipid-lowering } \\
\text { treatment, and antihypertensive treatment. }\end{array}$ \\
\hline
\end{tabular}

b There were 16 prospective cohort studies comprising 8729 cancer mortality cases among 10,794 participants in relation to 25-hydroxyvitamin D. EMAS: the European Male Ageing Study; GPTL: the General Population Trial of Linxian; CAIFOS: Calcuim Intake Fracture Outcome Study; ATBC: The Alpha-Tocopherol, Beta-Carotene Cancer Prevention Study; MrOS: Osteoporotic Fractures in Men study; GFR: Glomerular filtration rate; TS: Tromsø Study; NHANES III: Third National Health and Nutritional Examination Survey; LURIC: The Ludwigshafen Risk and Cardiovascular Health study; WHI: the Women's Health Initiative; ESTHER: Epidemiological investigations of the chances of preventing, recognizing early and optimally treating chronic diseases in an elderly population; SCCS: The Southern Community Cohort Study; Health ABC: the Health, Aging, and Body Composition study ; ULSAM: The Uppsala Longitudinal Study of Adult Men; CaD: calcium and vitamin D; IL-6: interleukin-6. 
In the meta-analysis combining results of eight independent cohort studies [13,30-32,41-44], $25(\mathrm{OH}) \mathrm{D}$ was marginally associated with cancer risk, with a significant between-study heterogeneity (Summary RR $=0.86 ; 95 \%$ CI: 0.73, 1.02; $\mathrm{I}^{2}=70.8 \% ; p=0.001$ ) (Figure 2). Regarding total cancer mortality, the summary estimate found an inverse association, with a significant between-study heterogeneity [33,43,45-58] (Summary RR $=0.81 ; 95 \%$ CI: 0.71, 0.93; $\mathrm{I}^{2}=48.8 \%, p=0.012$ ) (Figure 3). Dose-response analysis indicated that the risk of cancer incidence was reduced by $7 \%(\mathrm{RRs}=0.93$; 95\% CI: 0.91, 0.96) (Figure 4), and the risk of cancer mortality was reduced by $2 \%$ (RRs $=0.98$; 95\% CI: 0.97, 0.99) for each $20 \mathrm{nmol} / \mathrm{L}$ increment of 25-hydroxyvitamin D concentration (Figure 5).

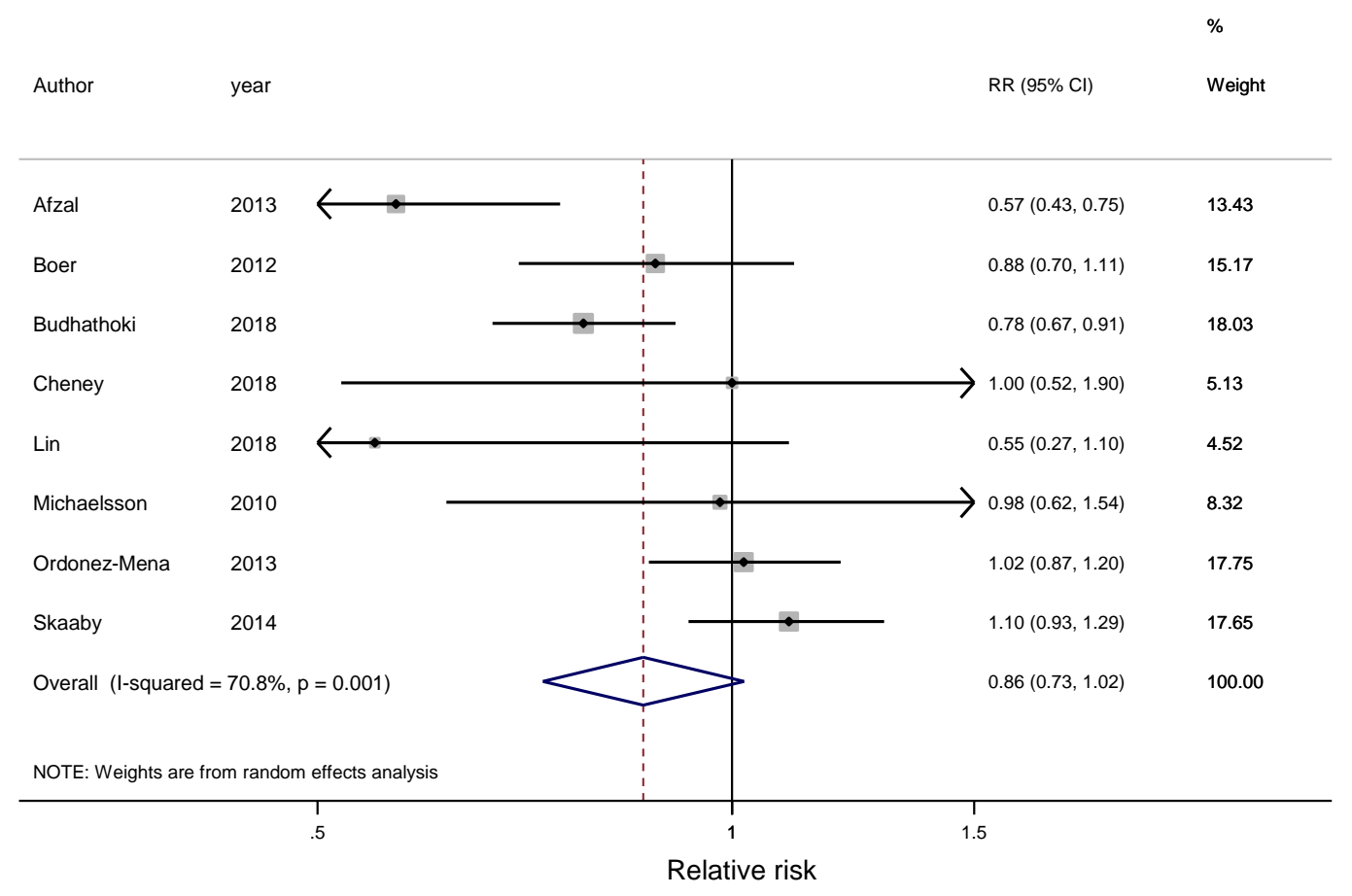

Figure 2. Forest plot to quantify the association between 25-hydroxyvitamin D and total cancer incidence. The summary relative risk was calculated using a random-effects model. The diamonds denote the summary risk estimate, and the horizontal lines represent $95 \%$ confidence interval (CI). Abbreviations: RR, summary relative risk.

\subsection{Subgroup Analysis}

In terms of total cancer incidence, subgroup analysis, stratified by region, indicated that the pooled effect of 25-hydroxyvitamin D was significantly associated with cancer incidence in Asia [30,31] (Pooled RR $=0.77 ; 95 \%$ CI: 0.66, 0.89; $I^{2}=76.0 \% ; p=0.341$ ), but there was no significant correlation in Europe [13,32,41-43] (Pooled RR $=0.91 ; 95 \%$ CI: 0.71, 1.16; $\mathrm{I}^{2}=0.002 ; p=0.002$ ). Studies were divided according to gender, and the male group $[13,31,42,43]$ showed a borderline association between 25-hydroxyvitamin D and cancer risk (Pooled RR $=0.75 ; 95 \%$ CI: $0.55,1.01 ; \mathrm{I}^{2}=65.0 \% ; p=0.025$ ), but there was no significant correlation in the female subgroup [31,42] (Pooled RR $=0.80 ; 95 \%$ CI: $\left.0.35,1.82 ; \mathrm{I}^{2}=75.8 \% ; p=0.042\right)$. The studies were stratified by the study quality, indicating that there was a borderline association between 25-hydroxyvitamin $\mathrm{D}$ and cancer risk in the high-quality group [13,30,31,41] (Pooled RR $=0.80,95 \%$ CI: $0.63,1.01$ ), but there was no significant correlation in the moderate-quality group (Table S3). 


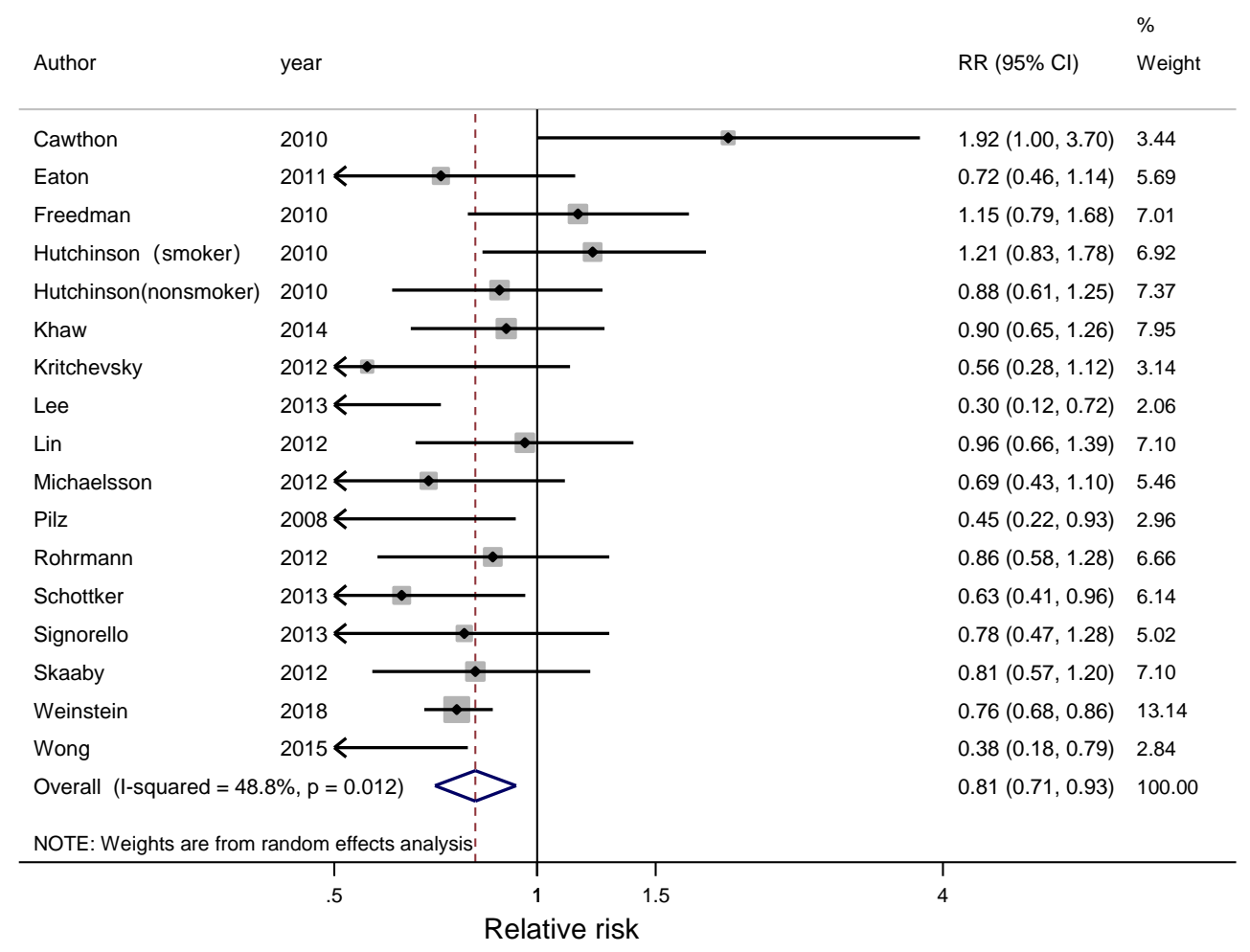

Figure 3. Forest plot to quantify the association between 25-hydroxyvitamin D and total cancer mortality. The diamonds denote the summary risk estimate, and the horizontal lines represent $95 \%$ CI. Abbreviations: RR, relative risk.

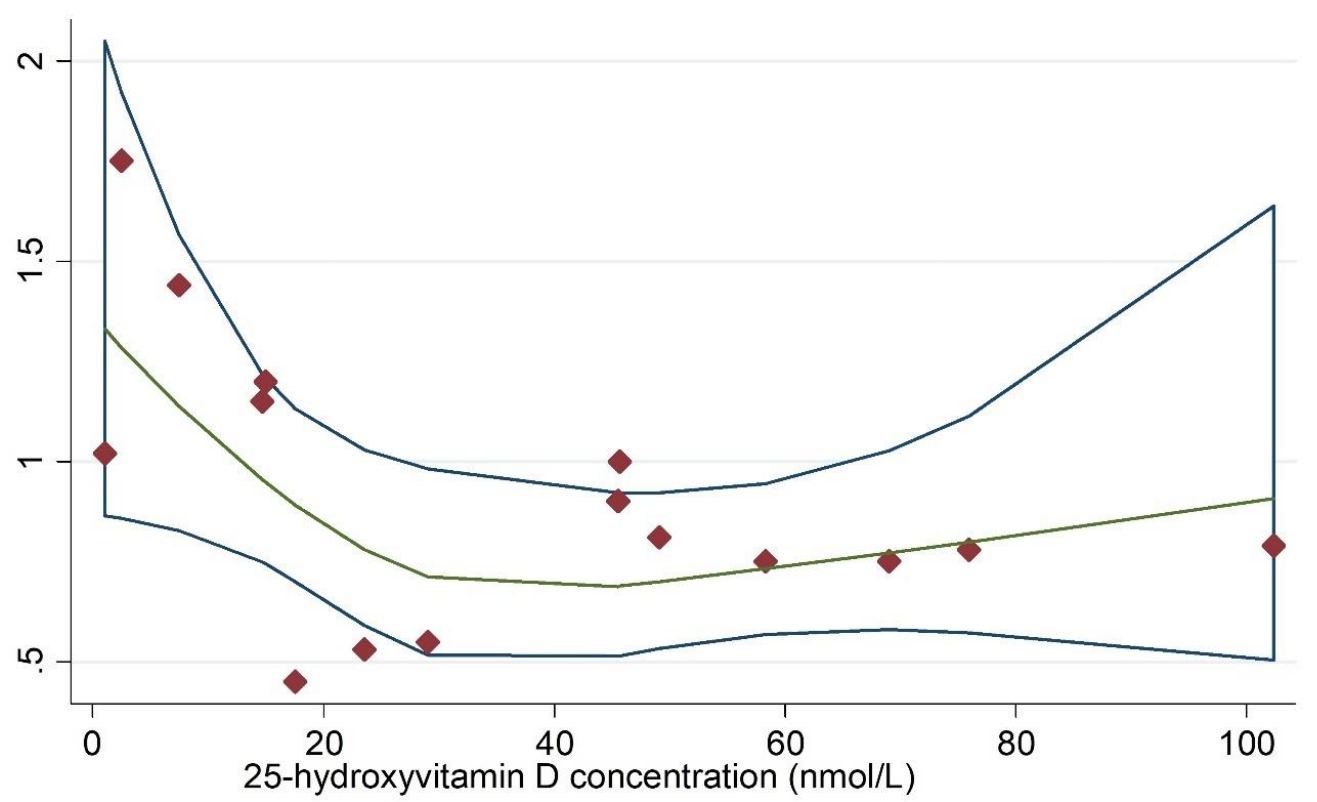

Figure 4. Dose-response analysis for vitamin D concentration and cancer incidence. Adjusted RRs from each exposure quantile of $25(\mathrm{OH}) \mathrm{D}$ concentration in included individual studies were represented by the diamonds, and corresponding intervals (CIs) were represented by the blue trendline. Abbreviations: RR, relative risk. The green line indicated the dose-response linear trend between $25(\mathrm{OH}) \mathrm{D}$ concentration and risk of cancer incidence by use of variance-weighted least squares regression of fixed effect model. 


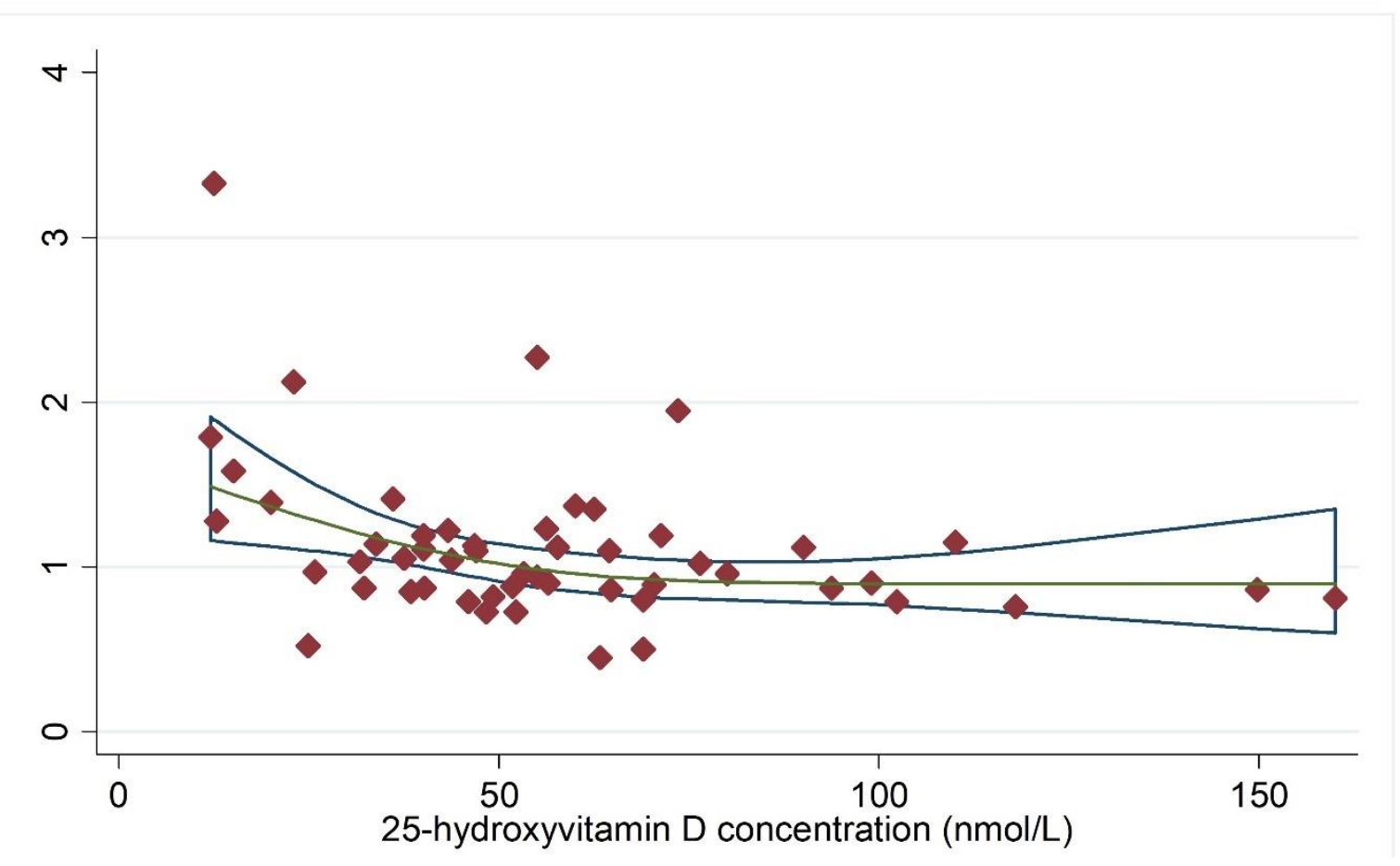

Figure 5. Dose-response analysis for vitamin D concentration and cancer mortality. Adjusted RRs from each exposure quantile of $25(\mathrm{OH}) \mathrm{D}$ concentration in included individual studies were represented by the diamonds, and corresponding intervals (CIs) were represented by the blue trendline. Abbreviations: RR, relative risk. The green line indicated the dose-response linear trend between $25(\mathrm{OH}) \mathrm{D}$ concentration and risk of cancer mortality by use of variance-weighted least squares regression of fixed effect model.

Similarly, the summary estimate of 25-hydroxyvitamin D was inversely associated with cancer mortality in the female group [31,47,50,52,56] (Pooled RR $=0.72 ; 95 \%$ CI: 0.52, 0.98; $\mathrm{I}^{2}=56.6 \%$; $p=0.075$ ), but not in the male group [31,33,43,45,48,50] (Pooled RR $=0.90 ; 95 \%$ CI: $0.73,1.12 ; \mathrm{I}^{2}=78.7 \%$; $p<0.001)$. When the articles were divided into subgroups by the study quality, 25 -hydroxyvitamin $\mathrm{D}$ was negatively correlated with cancer mortality in the high-quality subgroup [33,46,47,49-51,53-58] (Pooled RR $=0.82 ; 95 \%$ CI: 0.71, $0.95 ; \mathrm{I}^{2}=48.8 \% ; p=0.058$ ), but there was no significant correlation in the moderate-quality subgroup [34,44,46,53] (Pooled RR $=0.78 ; 95 \%$ CI: $0.52,1.18 ; \mathrm{I}^{2}=40.9 \% ; p=0.062$ ). The studies stratified by region showed that there was a significantly association between vitamin D concentration and cancer mortality in Europe $[33,43,45,49,51,53,54,56,57]$ (Pooled RR $=0.79,95 \%$ CI: $\left.0.68,0.90 ; \mathrm{I}^{2}=38.1 \% ; p=0.104\right)$, and a marginal association in the US $[48,49,51,53,56,58]$ (Pooled $\mathrm{RR}=0.83 ; 95 \%$ CI: 0.56, $1.21 ; \mathrm{I}^{2}=48.8 \% ; p=0.012$ ) (Supplementary Table S4).

\subsection{Sensitivity Analysis and Publication Bias}

In a sensitivity analysis, each study was sequentially deleted, and the remaining data were re-calculated. The results showed that the summary estimate was not substantially driven, to the exclusion of any one study. In publication bias analysis, non-significant publication bias was observed using Egger's regression test (Supplementary Figures S1 and S2).

\section{Discussion}

Analyses of 8 studies on cancer incidence and 16 studies on cancer mortality, showing that 25-hydroxyvitamin D is marginally associated with cancer risk and inversely associated with mortality, were pooled. The dose-response analysis showed that cancer risk decreased by $7 \%$ (95\% CI: 0.90, 0.95), with a $20 \mathrm{nmol} / \mathrm{L}$ increment of 25 -hydroxyvitamin $\mathrm{D}$, and cancer mortality decreased by $2 \%(95 \% \mathrm{CI}$ : $0.97,0.99$ ), with a $20 \mathrm{nmol} / \mathrm{L}$ increment of 25 -hydroxyvitamin D. In fact, a meta-analysis of a prospective 
cohort study on the relationship between vitamin D concentration and cancer incidence and mortality was performed in 2013 [26]. Based on the summary estimates, the present study confirms the findings presented in the previous meta-analysis.

This study excluded the study of Giovannucci et al. [59] because it predicted, rather than measured, 25(OH)D concentrations. We also excluded the retrospective cohort study of Krause et al. [60]. Of course, we have supplemented and updated the previous meta-analysis and included more studies [30,31,33,41,45,47,56-58]. In addition, a meta-analysis of randomized controlled trials was recently conducted. Goulao et al. [61] concluded that vitamin D supplementation alone reduces the incidence of cancer or cancer mortality, and Keum et al. [62] indicated that vitamin D supplementation significantly reduced total cancer mortality but did not reduce total cancer incidence. The development of cancer is a long-term and gradual process, while the intervention time of randomized controlled trials is limited.

As can be observed in our study, several studies have reported null associations between vitamin D concentration and cancer incidence or mortality [13,30,33,45,47,51,54]. However, other studies have reported modest statistically significant reductions in cancer risk or mortality, with increments of 25-hydroxyvitamin D concentration [31,32,41-43,46,48-50,52,53,55-58]. At the same time, studies found that a higher 25-hydroxyvitamin D concentration is marginally associated with the cancer incidence in males, but no correlation was found in females. In terms of cancer mortality, a higher 25-hydroxyvitamin D is inversely associated with the cancer incidence in females, but no correlation was found in males. The reason may be that few studies have focused on the gender segregation. While the inclusive prospective studies have shown controversial and inconsistent associations, the summary estimate provided substantial evidence that a higher 25-hydroxyvitamin D is associated with a lower incidence and mortality.

The inverse association between 25-hydroxyvitamin D and cancer incidence and mortality is biologically plausible. Existing studies have shown that vitamin D regulates the entire process of tumorigenesis, from initiation to stabilization, and the interaction with the cellular microenvironment $[20,23,62]$. Vitamin D regulates multiple signaling pathways through its active form, $1,25(\mathrm{OH}) 2 \mathrm{D}$, and shows a direct effect on cell proliferation, differentiation, and cell death. In addition, vitamin $\mathrm{D}$ has been shown to have anti-inflammatory, oxidative stress, and immune response, which may help to inhibit tumor cell initiation and progression [42,43]. These laboratory studies provide possible mechanisms through which vitamin D may be associated with reduced cancer incidence and mortality.

Our meta-analysis may have several limitations which must be taken into account. First, due to the observational nature of the data, it is possible that the observed significant inverse association between 25-hydroxyvitamin D and cancer incidence and mortality could be due to unmeasured or residual confounding. Second, the reduced cancer incidence and mortality may be associated with other health behaviors (e.g., balanced nutrition, adequate sleep, exercise and so on). A further limitation was that the eligible studies varied in several respects, including differences in the study populations, baseline comorbidities, and measurement of the exposure, and it is possible that methodological differences might have confounded the differences recorded across subgroups of the study. Not all prospective studies are conducted in the general population (e.g., the study of Pilz et al. [50] was conducted in the Patients Referred to Coronary Angiography).

The merits of this research should be emphasized. First, we have included more research than the previous meta-analyses. The large sample size of the meta-analysis provided powerful statistical power for the quantitative evaluation of this association. Second, eligible studies are medium- and high-quality prospective cohort studies that reduce the likelihood of recall errors and selection biases. Third, the confounding factors of the individual studies have been greatly adjusted to minimize biases. Besides, the follow-up of the prospective cohort studies is sufficiently long. Furthermore, dose-response analysis was also conducted to provide substantial evidence that vitamin D concentration is associated with cancer incidence and mortality, with a dose-dependent trend. 


\section{Conclusions}

The present study provides compelling evidence that a higher 25-hydroxyvitamin D concentration is marginally associated with cancer incidence and inversely associated with cancer mortality. Since the majority of the prospective studies were performed in Western countries, further prospective studies should be conducted in other regions, with different ethnic origins, to confirm these associations.

Supplementary Materials: The following are available online at http://www.mdpi.com/2072-6643/11/10/2295/s1, Figure S1: Sensitivity analysis with respect to vitamin D concentration and cancer incidence; Figure S2: Sensitivity analysis with respect to vitamin D concentration and cancer mortality; Table S1 Quality assessment of studies investigating 25(OH)D and cancer risk, according to the Newcastle-Ottawa Scale; Table S2. Quality assessment of studies investigating $25(\mathrm{OH}) \mathrm{D}$ and cancer mortality, according to the Newcastle-Ottawa Scale; Table S3: Subgroup and meta-regression analyses for cancer incidence; Table S4: Subgroup and meta-regression analyses for cancer mortality.

Author Contributions: J.H. and X.G. have screened the literature and selected papers for inclusion in the review. J.H. and X.G. have contributed to data extraction. All authors contributed to the development of this manuscript and read and approved the final version.

Funding: This work is supported by the National Natural Science Foundation of China $(81573137,81872605)$; Key Research and Development Project of Shandong Province (2017GSF18167). The funders have no role in study design, data collection and analysis, decision to publish, or preparation of the manuscript.

Conflicts of Interest: The authors declare no conflict of interest.

\section{References}

1. Bray, F.; Ferlay, J.; Soerjomataram, I.; Siegel, R.L.; Torre, L.A.; Jemal, A. Global cancer statistics 2018: Globocan estimates of incidence and mortality worldwide for 36 cancers in 185 countries. CA Cancer J. Clin. 2018, 68, 394-424. [CrossRef] [PubMed]

2. Abubakar, I.I.; Tillmann, T.; Banerjee, A. Global, regional, and national age-sex specific all-cause and cause-specific mortality for 240 causes of death, 1990-2013: A systematic analysis for the global burden of disease study 2013. Lancet 2015, 385, 117-171.

3. Murray, C.J.; Lopez, A.D. Mortality by cause for eight regions of the world: Global burden of disease study. Lancet 1997, 349, 1269-1276. [CrossRef]

4. Allemani, C.; Weir, H.K.; Carreira, H.; Harewood, R.; Spika, D.; Wang, X.S.; Bannon, F.; Ahn, J.V.; Johnson, C.J.; Bonaventure, A. Global surveillance of cancer survival 1995-2009: Analysis of individual data for 25676 887 patients from 279 population-based registries in 67 countries (concord-2). Lancet 2015, 385, 977-1010. [CrossRef]

5. Coleman, M.P.; Gatta, G.; Verdecchia, A.; Estève, J.; Berrino, F. Eurocare-3 summary: Cancer survival in europe at the end of the 20th century. Ann. Oncol. 2003, 14 (Suppl. 5) (Suppl. 5), v128-v149. [CrossRef]

6. Edwards, B.K.; Anne-Michelle, N.; Mariotto, A.B.; Simard, E.P.; Boscoe, F.P.; Jane, H.S.; Ahmedin, J.; Hyunsoon, C.; Anderson, R.N.; Kohler, B.A. Annual report to the nation on the status of cancer, 1975-2010, featuring prevalence of comorbidity and impact on survival among persons with lung, colorectal, breast, or prostate cancer. Cancer 2014, 120, 1290-1314. [CrossRef] [PubMed]

7. Kitson, M.T.; Roberts, S.K. D-livering the message: The importance of vitamin d status in chronic liver disease. J. Hepatol. 2012, 57, 897-909. [CrossRef] [PubMed]

8. Wang, Y.; Zhu, J.; Deluca, H.F. Where is the vitamin d receptor? Arch. Biochem. Biophys. 2012, 523, $123-133$. [CrossRef]

9. Pandolfi, F.; Franza, L.; Mandolini, C.; Conti, P. Immune modulation by vitamin d: Special emphasis on its role in prevention and treatment of cancer. Clin. Ther. 2017, 39, 884-893. [CrossRef]

10. Garland, C.F.; Garland, F.C. Do sunlight and vitamin d reduce the likelihood of colon cancer? Int. J. Epidemiol. 1980, 9, 227-231. [CrossRef]

11. Fedirko, V.; Duarte-Salles, T.; Bamia, C.; Trichopoulou, A.; Aleksandrova, K.; Trichopoulos, D.; Trepo, E.; Tjonneland, A.; Olsen, A.; Overvad, K.; et al. Prediagnostic circulating vitamin d levels and risk of hepatocellular carcinoma in european populations: A nested case-control study. Hepatology 2014, 60, 1222-1230. [CrossRef] [PubMed] 
12. O'Brien, K.M.; Sandler, D.P.; Taylor, J.A.; Weinberg, C.R. Serum vitamin D and risk of breast cancer within five years. Environ. Health Perspect. 2017, 125, 077004. [CrossRef] [PubMed]

13. Afzal, S.; Bojesen, S.E.; Nordestgaard, B.G. Low plasma 25-hydroxyvitamin d and risk of tobacco-related cancer. Clin. Chem. 2013, 59, 771-780. [CrossRef] [PubMed]

14. Marco, G.; Danila, D.M.; Maurizio, L.G.; Stefania, A.; Marilena, C.; Carla, F.; Tumminello, F.M.; Gaetano, L. Vitamin d in cancer chemoprevention. Pharm. Biol. 2015, 53, 1399-1434.

15. Elzbieta, G.; Studzinski, G.P. Vitamin D and differentiation in cancer. Crit. Rev. Clin. Lab. Sci. 2009, 46, 190.

16. Haussler, M.R.; Whitfield, G.K.; Kaneko, I.; Haussler, C.A.; Hsieh, D.; Hsieh, J.C.; Jurutka, P.W. Molecular mechanisms of vitamin d action. Calcif. Tissue Int. 2013, 92, 77-98. [CrossRef]

17. Sam, S.; Sitrin, M.D. Vitamin D's role in cell proliferation and differentiation. Nutr. Rev. 2010, 66, S116-S124.

18. Jeon, S.M.; Shin, E.A. Exploring vitamin D metabolism and function in cancer. Exp. Mol. Med. 2018, 50, 20. [CrossRef]

19. Slominski, A.T.; Brozyna, A.A.; Zmijewski, M.A.; Jozwicki, W.; Jetten, A.M.; Mason, R.S.; Tuckey, R.C.; Elmets, C.A. Vitamin D signaling and melanoma: Role of vitamin D and its receptors in melanoma progression and management. Lab. Investig. 2017, 97, 706-724. [CrossRef]

20. David, F.; Krishnan, A.V.; Srilatha, S.; Edward, G.; Feldman, B.J. The role of vitamin d in reducing cancer risk and progression. Nat. Rev. Cancer 2014, 14, 342-357.

21. Krishnan, A.V.; David, F. Molecular pathways mediating the anti-inflammatory effects of calcitriol: Implications for prostate cancer chemoprevention and treatment. Endocr. Relat. Cancer 2010, 17, R19-R38. [CrossRef] [PubMed]

22. Carlien, L.; Lieve, V.; Annemieke, V. Antineoplastic effects of 1,25(oh)2d3 and its analogs in breast, prostate and colorectal cancer. Endocr. Relat. Cancer 2013, 20, R31-R47.

23. Swami, S.; Krishnan, A.V.; Feldman, D. Vitamin D metabolism and action in the prostate: Implications for health and disease. Mol. Cell. Endocrinol. 2011, 347, 61-69. [CrossRef] [PubMed]

24. Fleet, J.C.; DeSmet, M.; Johnson, R.; Li, Y. Vitamin D and cancer: A review of molecular mechanisms. Biochem. J. 2012, 441, 61-76. [CrossRef] [PubMed]

25. Zinser, G.M.; Sundberg, J.P.; Welsh, J.E. Vitamin d3 receptor ablation sensitizes skin to chemically induced tumorigenesis. Carcinogenesis 2002, 23, 2103-2109. [CrossRef] [PubMed]

26. Ordonez-Mena, J.M.; Chen, T.; Schottker, B.; Arndt, V.; Brenner, H. Circulating 25-hydroxyvitamin d serum concentration and total cancer incidence and mortality: A systematic review and meta-analysis. Prev. Med. 2013, 57, 753-764.

27. Gaksch, M.; Jorde, R.; Grimnes, G.; Joakimsen, R.; Schirmer, H.; Wilsgaard, T.; Mathiesen, E.B.; Njølstad, I.; Løchen, M.L.; März, W. Vitamin d and mortality: Individual participant data meta-analysis of standardized 25-hydroxyvitamin d in 26916 individuals from a european consortium. PLoS ONE 2017, 12, e0170791. [CrossRef]

28. Schöttker, B.; Jorde, R.; Peasey, A.; Thorand, B.; Jansen, E.H.; Ld, G.; Streppel, M.; Gardiner, J.; Ordóñez-Mena, J.M.; Perna, L. Vitamin d and mortality: Meta-analysis of individual participant data from a large consortium of cohort studies from europe and the united states. BMJ 2014, 348, g3656. [CrossRef] [PubMed]

29. Chowdhury, R.; Kunutsor, S.; Vitezova, A.; Oliver-Williams, C.; Chowdhury, S.; Kiefte-de-Jong, J.C.; Khan, H.; Baena, C.P.; Prabhakaran, D.; Hoshen, M.B.; et al. Vitamin d and risk of cause specific death: Systematic review and meta-analysis of observational cohort and randomised intervention studies. BMJ 2014, 348, g1903. [CrossRef]

30. Budhathoki, S.; Hidaka, A.; Yamaji, T.; Sawada, N.; Tanaka-Mizuno, S.; Kuchiba, A.; Charvat, H.; Goto, A.; Kojima, S.; Sudo, N.; et al. Plasma 25-hydroxyvitamin d concentration and subsequent risk of total and site specific cancers in japanese population: Large case-cohort study within japan public health center-based prospective study cohort. BMJ 2018, 360, k671. [CrossRef]

31. Lin, T.; Song, Y.; Zhang, X.; Guo, H.; Liu, L.; Zhou, Z.; Wang, B.; Tang, G.; Liu, C.; Yang, Y.; et al. Plasma 25-hydroxyvitamin $\mathrm{D}$ concentrations and risk of incident cancer in adults with hypertension: A nested case-control study. Clin. Nutr. 2018. [CrossRef] [PubMed]

32. Cheney, C.P.; Thorand, B.; Huth, C.; Berger, K.; Peters, A.; Seifert-Klauss, V.; Kiechle, M.; Strauch, K.; Quante, A.S. The association between serum 25-hydroxyvitamin d and cancer risk: Results from the prospective kora f4 study. Oncol. Res. Treat. 2018, 41, 117-121. [CrossRef] [PubMed] 
33. Weinstein, S.J.; Mondul, A.M.; Yu, K.; Layne, T.M.; Abnet, C.C.; Freedman, N.D.; Stolzenberg-Solomon, R.Z.; Lim, U.; Gail, M.H.; Albanes, D. Circulating 25-hydroxyvitamin d up to 3 decades prior to diagnosis in relation to overall and organ-specific cancer survival. Eur. J. Epidemiol. 2018, 33, 1087-1099. [CrossRef] [PubMed]

34. Zhong, Q.; Guo, P.; Zhong, G.C.; Zhong, S.L. Transforming the reference group of discrete correlated datain original study of dose response meta analysis. Evid. Basedmed. 2016, 16, 60-64.

35. Stang, A. Critical evaluation of the newcastle-ottawa scale for the assessment of the quality of nonrandomized studies in meta-analyses. Eur. J. Epidemiol. 2010, 25, 603-605. [CrossRef] [PubMed]

36. Liu, Q.; Cook, N.R.; Bergström, A.; Hsieh, C.C. A two-stage hierarchical regression model for meta-analysis of epidemiologic nonlinear dose-response data. Comput. Stat. Data Anal. 2009, 53, 4157-4167. [CrossRef]

37. Orsini, N.; Greenland, S. A procedure to tabulate and plot results after flexible modeling of a quantitative covariate. Stata J. 2011, 11, 1-29. [CrossRef]

38. Harrell, F.E.; Lee, K.L.; Pollock, B.G. Regression models in clinical studies: Determining relationships between predictors and response. J. Natl. Cancer Inst. 1988, 80, 1198-1202. [CrossRef] [PubMed]

39. Orsini, N.; Li, R.; Wolk, A.; Khudyakov, P.; Spiegelman, D. Meta-analysis for linear and nonlinear dose-response relations: Examples, an evaluation of approximations, and software. Am. J. Epidemiol. 2012, 175, 66-73. [CrossRef]

40. Seagroatt, V.; Stratton, I. Bias in meta-analysis detected by a simple, graphical test. Test had $10 \%$ false positive rate. BMJ Br. Med. J. 1997, 316, 469-471.

41. Skaaby, T.; Husemoen, L.L.; Thuesen, B.H.; Pisinger, C.; Jorgensen, T.; Roswall, N.; Larsen, S.C.; Linneberg, A. Prospective population-based study of the association between serum 25-hydroxyvitamin-d levels and the incidence of specific types of cancer. Cancer Epidemiol. Biomark. Prev. 2014, 23, 1220-1229. [CrossRef] [PubMed]

42. Ordonez-Mena, J.M.; Schottker, B.; Haug, U.; Muller, H.; Kohrle, J.; Schomburg, L.; Holleczek, B.; Brenner, H. Serum 25-hydroxyvitamin d and cancer risk in older adults: Results from a large german prospective cohort study. Cancer Epidemiol. Biomark. Prev. 2013, 22, 905-916. [CrossRef] [PubMed]

43. Michaelsson, K.; Baron, J.A.; Snellman, G.; Gedeborg, R.; Byberg, L.; Sundstrom, J.; Berglund, L.; Arnlov, J.; Hellman, P.; Blomhoff, R.; et al. Plasma vitamin d and mortality in older men: A community-based prospective cohort study. Am. J. Clin. Nutr. 2010, 92, 841-848. [CrossRef] [PubMed]

44. De Bore, L.H.; Levin, G.; Roblnson-Cohen, C.; Biggs, M.L.; Hoofnagle, A.; Siscovick, D.S.; Kestenbaum, B. Serum 25-hydroxyvitamin d concentration and risk for major clinical disease events in a community-based population of older adults a cohort study. Ann. Intern. Med. 2012, 156, 627-634. [CrossRef] [PubMed]

45. Lee, D.M.; Vanderschueren, D.; Boonen, S.; O’Neill, T.W.; Pendleton, N.; Pye, S.R.; Ravindrarajah, R.; Gielen, E.; Claessens, F.; Bartfai, G.; et al. Association of 25-hydroxyvitamin d, 1,25-dihydroxyvitamin d and parathyroid hormone with mortality among middle-aged and older european men. Age Ageing 2014, 43, 528-535. [CrossRef]

46. Lin, S.W.; Chen, W.; Fan, J.H.; Dawsey, S.M.; Taylor, P.R.; Qiao, Y.L.; Abnet, C.C. Prospective study of serum 25-hydroxyvitamin d concentration and mortality in a chinese population. Am. J. Epidemiol. 2012, 176, 1043-1050. [CrossRef]

47. Wong, G.; Lim, W.H.; Lewis, J.; Craig, J.C.; Turner, R.; Zhu, K.; Lim, E.M.; Prince, R. Vitamin d and cancer mortality in elderly women. BMC Cancer 2015, 15, 106. [CrossRef]

48. Cawthon, P.M.; Parimi, N.; Barrett-Connor, E.; Laughlin, G.A.; Ensrud, K.E.; Hoffman, A.R.; Shikany, J.M.; Cauley, J.A.; Lane, N.E.; Bauer, D.C.; et al. Serum 25-hydroxyvitamin d, parathyroid hormone, and mortality in older men. J. Clin. Endocrinol. Metab. 2010, 95, 4625-4634. [CrossRef]

49. Hutchinson, M.S.; Grimnes, G.; Joakimsen, R.M.; Figenschau, Y.; Jorde, R. Low serum 25-hydroxyvitamin $\mathrm{d}$ levels are associated with increased all-cause mortality risk in a general population: The tromso study. Eur. J. Endocrinol. 2010, 162, 935-942. [CrossRef]

50. Freedman, D.M.; Looker, A.C.; Abnet, C.C.; Linet, M.S.; Graubard, B.I. Serum 25-hydroxyvitamin d and cancer mortality in the nhanes iii study (1988-2006). Cancer Res. 2010, 70, 8587-8597. [CrossRef]

51. Pilz, S.; Dobnig, H.; Winklhofer-Roob, B.; Riedmuller, G.; Fischer, J.E.; Seelhorst, U.; Wellnitz, B.; Boehm, B.O.; Marz, W. Low serum levels of 25-hydroxyvitamin d predict fatal cancer in patients referred to coronary angiography. Cancer Epidemiol. Biomark. Prev. 2008, 17, 1228-1233. [CrossRef] [PubMed] 
52. Eaton, C.B.; Young, A.; Allison, M.A.; Robinson, J.; Martin, L.W.; Kuller, L.H.; Johnson, K.C.; Curb, J.D.; Van Horn, L.; McTiernan, A.; et al. Prospective association of vitamin d concentrations with mortality in postmenopausal women: Results from the women's health initiative (whi). Am. J. Clin. Nutr. 2011, 94, 1471-1478. [CrossRef] [PubMed]

53. Skaaby, T.; Husemoen, L.L.; Pisinger, C.; Jorgensen, T.; Thuesen, B.H.; Fenger, M.; Linneberg, A. Vitamin d status and cause-specific mortality: A general population study. PLoS ONE 2012, 7, e52423. [CrossRef] [PubMed]

54. Schottker, B.; Haug, U.; Schomburg, L.; Kohrle, J.; Perna, L.; Muller, H.; Holleczek, B.; Brenner, H. Strong associations of 25-hydroxyvitamin d concentrations with all-cause, cardiovascular, cancer, and respiratory disease mortality in a large cohort study. Am. J. Clin. Nutr. 2013, 97, 782-793. [CrossRef] [PubMed]

55. Signorello, L.B.; Han, X.; Cai, Q.; Cohen, S.S.; Cope, E.L.; Zheng, W.; Blot, W.J. A prospective study of serum 25-hydroxyvitamin d levels and mortality among african americans and non-african americans. Am. J. Epidemiol. 2013, 177, 171-179. [CrossRef]

56. Khaw, K.T.; Luben, R.; Wareham, N. Serum 25-hydroxyvitamin d, mortality, and incident cardiovascular disease, respiratory disease, cancers, and fractures: A 13-y prospective population study. Am. J. Clin. Nutr. 2014, 100, 1361-1370. [CrossRef]

57. Kritchevsky, S.B.; Tooze, J.A.; Neiberg, R.H.; Schwartz, G.G.; Hausman, D.B.; Johnson, M.A.; Bauer, D.C.; Cauley, J.A.; Shea, M.K.; Cawthon, P.M.; et al. 25-hydroxyvitamin d, parathyroid hormone, and mortality in black and white older adults: The health abc study. J. Clin. Endocrinol. Metab. 2012, 97, 4156-4165. [CrossRef]

58. Rohrmann, S.; Braun, J.; Bopp, M.; Faeh, D.; Swiss National, C. Inverse association between circulating vitamin $\mathrm{d}$ and mortality-Dependent on sex and cause of death? Nutr. Metab. Cardiovasc. Dis. 2013, 23, 960-966. [CrossRef]

59. Giovannucci, E.; Liu, Y.; Rimm, E.B.; Hollis, B.W.; Fuchs, C.S.; Stampfer, M.J.; Willett, W.C. Prospective study of predictors of vitamin d status and cancer incidence and mortality in men. J. Natl. Cancer Inst. 2006, 98, 451-459. [CrossRef]

60. Krause, R.; Schober-Halstenberg, H.J.; Edenharter, G.; Haas, K.; Roth, H.J.; Frei, U. Vitamin D status and mortality of german hemodialysis patients. Anticancer Res. 2012, 32, 391-396.

61. Goulao, B.; Stewart, F.; Ford, J.A.; MacLennan, G.; Avenell, A. Cancer and vitamin d supplementation: A systematic review and meta-analysis. Am. J. Clin. Nutr. 2018, 107, 652-663. [CrossRef] [PubMed]

62. Keum, N.; Giovannucci, E. Vitamin D supplements and total cancer incidence and mortality a meta-analysis of randomized controlled trials. Ann. Oncol. 2019, 30, 733-743. [CrossRef] [PubMed] 